\title{
Экспертиза
}

ПОСОХОВА Анастасия Владиславовна - доктор психологических наук, доцент кафедры педагогики и психологии МИРЭА - Российского технологического университета (119454, Россия, 2. Москва, nр-кт Вернадского, 78; aposohova@таil.ru)

\section{ПСИХОЛОГИЯ КОНКУРЕНТОСПОСОБНОСТИ ПРЕДПРИНИМАТЕЛЕЙ КАК НОВАЯ НАУЧНАЯ ДИСЦИПЛИНА}

Аннотация. В статье представлены теоретические основания психологии конкурентоспособности предпринимателей как новой научной психологической дисциплины, проводится анализ содержания и признаков научной дисциплины, ее научного статуса, научных связей и отношений применительно к психологической разработке проблем конкурентоспособности предпринимателей.

Автор раскрывает содержание главных признаков, характеризующих принадлежность психологии конкурентоспособности предпринимателей к научным дисциплинам, дает определение психологии конкурентоспособности предпринимателей, описывает ее объект, предмет, цели, методы, проблематику. В статье показывается фундаментальность данной научной дисциплины, описываются перспективы развития психологии конкурентоспособности предпринимателей как новой научной дисциплины.

Ключевые слова: предприниматель, психология конкурентоспособности предпринимателей, новая научная дисциплина, структура научной дисциплины

$\mathrm{B}$ настоящее время проблема психологии конкурентоспособности предпринимателей выходит на передовые позиции в спектре проблем, связанных с предпринимательством и разработкой психологического основания эффективной предпринимательской деятельности. Проведены конструктивные фундаментальные и прикладные исследования по проблеме психологии предпринимательства, личности и деятельности предпринимателей в контексте их конкурентоспособности, а также непосредственные психологические исследования конкурентоспособности предпринимателей как важнейшего личностно-профессионального свойства. Расширяется объектная и предметная область таких исследований. Выявлены главные закономерности, осуществлены обобщения, разработана психологическая концепция конкурентоспособности предпринимателей. Все это свидетельствует о фундаментальности проблемы психологии конкурентоспособности предпринимателей. Полученные научные результаты позитивно приняты научной общественностью, востребованы практикой. Становится очевидным, что психология конкурентоспособности предпринимателей давно сформировалась как новое научное направление психологии предпринимательства, возникшее на стыке теории предпринимательства, психологии труда, социальной и экономической психологии, психологии развития и конкурентологии. Данное направление получило столь интенсивное развитие, что вышло на передовые научные позиции в системе психологических наук, изучающих предпринимательство. Кроме того, полученные теоретические и практические результаты, их высокая научная значимость сейчас дают основание утверждать, что психология конкурентоспособности предпринимателей является не только направлением психологии предпринимательства, но уже обладает всеми признаками научной дисциплины, а вернее, реально таковой является.

Психология конкурентоспособности предпринимателей как научная дисциплина соответствует по своему содержанию существующим определениям категории «научная дисциплина». Заметим, что существующие определения научной дисциплины ориентированы на методологический принцип дисциплинар- 
ности. В них прослеживается мысль о том, что научная дисциплина является аналогом конкретной науки или самостоятельной отраслью какой-либо науки, имеющей признаки отдельной науки. В частности, научной дисциплиной считается отдельная наука, входящая в научный комплекс в конкретной объектной и предметной области [Огурцов 1988]. Очевидно, что здесь речь идет о специальных науках, входящих в общую науку. Например, научной дисциплиной является психология труда, входящая в систему психологической науки.

Отличительной чертой научной дисциплины является сложно организованное, многоуровневое научное знание, обладающее собственным предметом, объектом, методами и традициями. Другими словами, научная дисциплина имеет свойства, характеризующие ее относительную научную самостоятельность. Научная дисциплина представляется и как базовая форма организации профессиональной науки, объединяющая на предметно-содержательном основании область научного знания, а также сообщество, занятое его производством и трансляцией ${ }^{1}$. Дисциплинарная форма организации науки является проявлением не только самостоятельности, но и инвариантности. По дисциплинарному принципу строится и система подготовки специалистов во всех сферах профессиональной деятельности.

Главными признаками научной дисциплины считаются единство дисциплинарного знания и способов исследования и действия, самостоятельные категории, теоретические и эмпирические области с собственными объектами, свой отличительный набор предположений, типичные схемы взаимодействий, профессиональная принадлежность и др.

В психологии можно встретить немало работ, представляющих собой обоснование какой-либо новой научной дисциплины. В частности, при обосновании акмеологии было дано ее определение, раскрыто содержание психологической зрелости, описана ее проблематика и актуальные задачи [Бодалев 1993]. Такой опыт следует использовать при обосновании психологии конкурентоспособности предпринимателей.

На данном этапе своего развития психология конкурентоспособности предпринимателей обладает отмеченными признаками и в первую очередь - единством дисциплинарного знания, направленного на создание психологических оснований конкурентоспособности предпринимателей.

Рассмотрим содержание психологии конкурентоспособности предпринимателей как новой научной дисциплины.

Психология конкурентоспособности предпринимателей является научной дисциплиной, возникшей на стыке теории и практики предпринимательства, прикладных направлений психологической науки (психологии труда, социальной психологии, психологии профессий, экономической психологии), акмеологии и конкурентологии, изучающей психологические феномены и закономерности конкурентоспособности предпринимателей, психологические направления ее развития. Данное определение является общим, отражающим нынешний уровень развития психологических знаний в этой области.

Целью психологии конкурентоспособности предпринимателей является создание научных психологических оснований продуктивного развития конкурентоспособности предпринимателей, их профессионализма, позитивной самореализации в предпринимательстве.

Теоретическим основанием психологии конкурентоспособности предпринимателей являются теоретические исследования в области общей психологии, психологии труда, экономической психологии; психологические исследования

\footnotetext{
1 Лебедев С.А. 2004. Философия науки: словарь основных терминов. М.: Академический проект. 320 с.
} 
профессионализма личности и деятельности; психологические исследования деятельности в особых и экстремальных условиях; теоретические исследования в области психологии управления; психологические исследования предпринимателей и предпринимательской деятельности; теоретические исследования в области конкурентологии и предпринимательства.

Методологическим основанием психологии конкурентоспособности предпринимателей являются подходы и принципы изучения психологически сложного объекта.

Главным объектом этой научной дисциплины является сама конкурентоспособность предпринимателей и ее психологические характеристики, при этом конкурентоспособность предпринимателей изучается на уровне общего, особенного и единичного (у предпринимателей как общественных индивидов, личностей, субъектов профессиональной деятельности и индивидуальностей). В этом отличительная особенность объекта данной научной дисциплины.

Предметом научной дисциплины являются психологические механизмы и закономерности конкурентоспособности предпринимателей, ее психологическая система, психологические детерминанты продуктивного развития конкурентоспособности предпринимателей.

В психологии конкурентоспособности предпринимателей как научной дисциплине обоснованы собственные научные категории, в частности конкурентоспособность личности и деятельности предпринимателей, полипрофессионализм и поликомпетентность в предпринимательстве, психологические инварианты профессионализма предпринимателей, деловая хватка и деловая активность предпринимателей и др., раскрыто и обосновано их психологическое содержание [Посохова 2014a; 2014б].

Разработка проблем психологии конкурентоспособности предпринимателей как научной дисциплины осуществляется с использованием различных методов - общенаучных (различные виды анализа, обобщений, классификаций, синтеза, моделирования и др.), теоретических и эмпирических методов психологии, ориентированных и скорректированных с учетом психологической сложности самих предпринимателей и их конкурентоспособности как объектов психологических исследований, специфики взаимодействия с ними.

Проблематика психологии конкурентоспособности предпринимателей отличается разнообразием: это психологические описания феномена конкурентоспособности предпринимателей, выявление устойчивых отношений и закономерностей, выявление психологических условий и факторов, способствующих или препятствующих повышению уровня конкурентоспособности предпринимателей, исследования гендерных отличий, выход на проблему способности к конкуренции и пр.

Психология конкурентоспособности предпринимателей как научная дисциплина, благодаря проведенным теоретическим и прикладным исследованиям, начинает приобретать фундаментальный характер. При разработке психологических оснований конкурентоспособности предпринимателей были разработаны различные психологические модели, выявлены закономерности проявления этого важнейшего личностно-профессионального свойства предпринимателей, созданы системные описания конкурентоспособности предпринимателей и ее психологических детерминантов, разработана обобщенная психологическая концепция конкурентоспособности предпринимателей.

В настоящее время становится очевидным, что психология конкурентоспособности предпринимателей как научная дисциплина имеет хорошую перспективу развития. Данное развитие направляется как логикой становления этой научной дисциплины, так и возрастающей потребностью в практических 
результатах, связанных с ее применением. Очевидно, что сама психологическая наука и практика весьма заинтересованы в том, чтобы развитие психологии конкурентоспособности предпринимателей как научной дисциплины было бы поступательным и результативным. Для того чтобы это произошло, необходимо определить главные направления развития данной научной дисциплины и их психологическое содержание, чтобы рационально сконцентрировать на них усилия.

Науковедческий опыт свидетельствует, что дальнейшее развитие какой-либо научной дисциплины обычно осуществляется по нескольким направлениям. Именно на них следует ориентировать психологию конкурентоспособности предпринимателей.

Первое из них связано с расширением объектного пространства психологии конкурентоспособности предпринимателей. В частности, необходимы углубленные исследования гендерных психологических аспектов конкурентоспособности предпринимателей, в т.ч. и рассмотрение гендера как одной из значимых социальных ролей. Важными являются психологические исследования изменений конкурентоспособности предпринимателей с возрастом и опытом работы. В многонациональной стране интерес представляют особенные этнические психологические проявления конкурентоспособности предпринимателей. Важно проводить психологические исследования конкурентоспособности в малом, среднем и большом бизнесе, в различных профессиональных сферах. Особое внимание следует уделить психологическим проявлениям конкурентоспособности в кризисных и экстремальных ситуациях. Это позволит обогатить сложившиеся представления относительно сущностных характеристик конкурентоспособности предпринимателей.

Второе направление связано с расширением предметного пространства проблемы конкурентоспособности предпринимателей. Требует углубленной разработки проблема предпринимательских способностей с выходом на обоснование способности к конкуренции, методы ее психологической диагностики, оценки и развития. Следует продолжить психологические исследования личностных смыслов конкуренции в предпринимательстве. Важно приступить к разработке проблемы психологических ресурсов конкурентоспособности предпринимателей, их восполнения и преумножения. Перспективными являются психологические исследования конкурентоспособности предпринимателей в различных условиях взаимодействий и отношений. К новым предметным областям относится дальнейшее психологическое изучение противоречий в развитии конкурентоспособности, профессиональных деформаций конкурентоспособных предпринимателей, их я-концепции.

Третье направление развития обусловливается необходимостью дальнейшей интеграции психологии конкурентоспособности предпринимателей с другими научными дисциплинами. Это позволит не только расширить объектную и предметную сферы психологии конкурентоспособности предпринимателей, но и обогатить разработанные модели и системные описания. Отметим наиболее перспективные направления взаимодействий. Так, в частности, большое значение инновационной деятельности в деле обеспечения конкурентоспособности предпринимателей требует более тесных связей с психологией творчества, психологическими путями раскрытия творческого потенциала, его восполнения и преумножения. Необходимость постоянного развития профессионализма предпринимателей, направленность на высшие достижения в этой профессиональной сфере обусловливают тесную связь с акмеологией. Предпринимательская деятельность осуществляется в условиях не только конкуренции, но и открытого противоборства, поэтому важны связи психологии конкурентоспособно- 
сти предпринимателей с конфликтологией. Важность качественной профессиональной подготовки предпринимателей с высоким уровнем психологической готовности обусловливает связи психологии конкурентоспособности предпринимателей с педагогикой. Такая интеграция, несомненно, должна обогатить содержание данной научной дисциплины.

Четвертое, и, пожалуй, самое важное направление развития психологии конкурентоспособности предпринимателей, связано с проведением углубленных теоретических обобщающих исследований. Большой объем полученных эмпирических результатов требует не только анализа, но и систематизации и обобщений, чтобы создать необходимый плацдарм для дальнейшего поступательного движения этой научной дисциплины. Теоретические обобщения должны быть логичными, убедительными и конструктивными. Таковым для психологии конкурентоспособности предпринимателей является разработка специальной психологической теории конкурентоспособности предпринимателей. Для разработки специальной психологической теории конкурентоспособности предпринимателей следует также использовать богатый опыт создания общих и частных теорий в психологии и других науках комплекса человекознания.

При создании специальной психологической теории конкурентоспособности предпринимателей необходимо уделить первоочередное внимание следующим направлениям научных исследований:

- выявлению новых психологических закономерностей конкурентоспособности предпринимателей;

- разработке психологических законов конкурентоспособности предпринимателей;

- созданию новых моделей, связанных с конкурентоспособностью предпринимателей, которые обладают высокими объяснительными и прогностическими свойствами и позволяют эффективно решать научные и практические задачи и совершенствовать уже разработанные;

- созданию психологических типологий конкурентоспособных предпринимателей;

- дальнейшей разработке проблемы поликомпетентности и полипрофессионализма предпринимателей;

- психологическому изучению вершинных достижений в предпринимательстве, описанию феномена профессионального «акме» в предпринимательстве;

- гендерным, возрастным, национальным и иным факторам конкурентоспособности предпринимателей;

- психологическим факторам развития инновационной активности и управлению ею;

- разработке психологической системы подбора по критерию конкурентоспособности.

Специальная психологическая теория конкурентоспособности предпринимателей позволит успешно решать многие проблемы и задачи, связанные с повышением эффективности предпринимательской деятельности.

Таковы отличительные особенности и научные перспективы новой научной дисциплины «психология конкурентоспособности предпринимателей». Заметим, что психология конкурентоспособности предпринимателей в настоящее время выходит также и на уровень учебной дисциплины - подготовлены учебные и методические пособия, учебные программы по данной дисциплине, осуществляется обучение и профессиональная переподготовка. 


\title{
Список литературы
}

Бодалев А.А. 1993. Акмеология как учебная и научная дисциплина. М.: Изд-во РАУ. 110 c.

Огурцов А.П. 1988. Дисциплинарная структура науки: генезис и обоснование. М.: Мысль. 256 с.

Посохова А.В. 2014а. Конкурентоспособность предпринимателей (психологоакмеологические аспекты проблемы.) М.: Изд-во АПКиППРО. 128 с.

Посохова А.В. 2014б. Конкурентоспособность предпринимателей: психолого-акмеологический взгляд на проблему. - Человеческий капитал. № 7(67). C. 83-86.

POSOKHOVAAnastasiya Vladislavovna, Dr.Sci.(Psych.), Associate Professorof the Chairof Pedagogics and Psychology, Moscow State Institute of Radio Engineering, Electronics and Automation (Technical University) (78 Vernadskogo Ave, Moscow, Russia, 119454; aposohova@mail.ru)

\section{THE PSYCHOLOGY OF COMPETITIVENESS OF ENTREPRENEURS AS A NEW SCIENTIFIC DISCIPLINE}

\begin{abstract}
The article presents the theoretical basis of the psychology of competitiveness of entrepreneurs as a new scientific psychological discipline. The author gives an analysis of the content and characteristics of the scientific discipline, its scientific status, scientific relations and relations with reference to psychological development of the problems of competitiveness of entrepreneurs.

The article discloses the contents of the main signs characterizing the belonging of the psychology of competitiveness of entrepreneurs to scientific disciplines; gives the definition of psychology the competitiveness of companies; describes its object, subject, goals, methods, issues. The author shows fundamental nature of this scientific discipline and describes the prospects of the development of psychology of competitiveness of entrepreneurs as a new scientific discipline.

Keywords: entrepreneur, psychology of competitiveness of entrepreneurs, new scientific discipline, structure of scientific discipline
\end{abstract}

